\title{
European Quaternary refugia: a factor in large carnivore extinction?
}

\author{
HANNAH J. O'REGAN,* ALAN TURNER and DAVID M. WILKINSON \\ School of Biological and Earth Sciences, Liverpool John Moores University, Liverpool L3 3AF, England
}

O'Regan, H. J., Turner, A. and Wilkinson, D. M. 2002. European Quaternary refugia: a factor in large carnivore extinction?. J. Quaternary Sci., Vol. 17 pp. 789-795. ISSN 0267-8179.

Received 17 April 2002; Revised 18 June 2002; Accepted 3 July 2002

\begin{abstract}
The extinction of large carnivores in Europe during the Quaternary is reviewed and the potential role of glacial refugia in these extinctions is investigated using the VORTEX model for population viability analysis. A model was built for a medium sized big cat similar to the extinct Panthera gombaszoegensis utilising life history data from the modern jaguar Panthera onca. This approach highlighted the potential importance of glacial refugia in the extinction process. Even model refugia the size of the Italian peninsula did not guarantee persistence of a population over a $1000 \mathrm{yr}$ time span, illustrating the role of chance in survival in such a refugium. An area the size of the largest Mediterranean island was unable to support a big cat population for a period of $1000 \mathrm{yr}$. The models also demonstrated the importance of inbreeding as a mechanism for extinction in refugia. It is suggested that repeated genetic bottlenecks during successive glaciations would tend to remove lethal recessive alleles from the population, increasing the probability of survival in refugia in subsequent glaciations. The history of extinction of large carnivores in the European Quaternary is interpreted in the light of these results. Copyright (@) 2002 John Wiley \& Sons, Ltd.
\end{abstract}

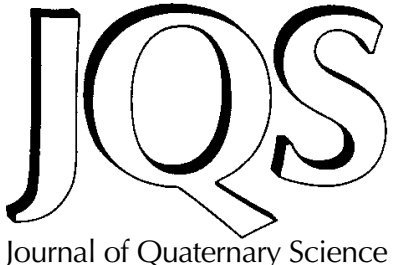

KEYWORDS: Pleistocene; felid; inbreeding; island populations; refugium.

\section{Introduction}

Since the nineteenth century it has been apparent that most members of the northern European temperate biota would have been unable to survive glacial periods in situ, the common assumption being that they inhabited southern Europe and North Africa during the cold stages (Geikie, 1881; Reid, 1899). The current consensus is that many of the European biota survived the glacial maxima in three large refugia in the Balkans, Italy and Iberia (Bennett et al., 1991; Willis, 1996; Hewitt, 1999), although recent work has suggested the possible presence of small populations of temperate tree species in refugia to the north of the Alps (Stewart and Lister, 2001).

Much attention has been paid to the patterns of postglacial migration from these refugia using fossil evidence such as pollen (Huntley and Webb, 1989) and more recently mtDNA analysis, which can pick up the dispersal patterns of various species some $13000 \mathrm{yr}$ after the last glaciation (e.g. Taberlet et al., 1998). Much less is known about the role of these refugia in promoting extinction, however, especially that of animals requiring large territories or forest environments. Although refugia have implications for the survival or speciation of the European microfauna, the survival of viable populations of large mammals is more

* Correspondence to: Dr Hannah J. O'Regan, School of Biological and Earth Sciences, Liverpool John Moores University, Liverpool L3 3AF, England.

E-mail: BESHOREG@livjm.ac.uk problematic. This particularly is the case for predators, which tend to be larger than their prey (Cohen et al., 1993) and consequently have smaller population densities. In this paper we review extinction in the European large carnivore guild and investigate potential mechanisms for these losses using modelling techniques current in conservation biology.

The Pleistocene covers a period of great change in large mammal populations. Although the ideas in this paper are applicable to many groups we will concentrate on the larger Carnivora, a group that has been well studied in recent years (e.g. Turner, 1995; Turner and Antón, 1996, 1997, 1999). As these animals require large home range sizes and are at the top of the foodchain they are likely to have been particularly susceptible to extinction in refugia. As an illustration of the diversity of this guild, by $500000 \mathrm{yr}$ ago there were five large felid species and three hyaenids in Europe (Turner, 1995). From observations of modern felids it is apparent that relatively large areas of land are required to provide enough resources in terms of habitat, prey and mating opportunities for a viable population of large cats to persist. To take an extreme example, the range size requirement of the Siberian tiger (Panthera tigris altaica) has been estimated between 100 and $400 \mathrm{~km}^{2}$ for females and 800 and $1000 \mathrm{~km}^{2}$ for males (Hoogesteijn and Mondolfi, 1992). From these figures it is evident that although glacial refugia may have provided an opportunity for speciation in small mammals (Bilton et al, 1998), they may have promoted extinction in large bodied species through a simple lack of space for a viable population. Applying techniques from 
conservation biology we will provide a first step in modelling the survival of a large solitary cat in a refugium using the extinct European jaguar-like cat Panthera gombaszoegensis as an example and life history data for the similarly sized modern jaguar (Panthera onca) as a base for the model parameters. We stress that the purpose of our model is explanatory rather than predictive with the aim of illustrating the principles of extinction and the potential for these techniques to be used more widely on palaeontological data.

\section{European large carnivore guild}

Several more detailed discussions of the guild structure and evolution have been published elsewhere (Turner, 1995; Turner and Antón, 1999), but in summary the European guild at the end of the Pliocene consisted of the flesh-eating machairodont cats, Homotherium latidens and Megantereon cultridens, the gracile hunting hyaena, Chasmaporthetes lunensis, and the large European cheetah, Acinonyx pardinensis. The only bone-destroying species present was the hyaenid Pliocrocuta perrieri, an animal about the size of a living spotted hyaena, Crocuta crocuta.

The beginning of the Pleistocene at ca. 1.8 Ma saw the local extinction of Chasmaporthetes lunensis and Pliocrocuta perrieri (although the latter reappeared in Europe in the Middle Pleistocene) and the first appearances of Panthera gombaszoegensis and the gigantic hyaenid Pachycrocuta brevirostris. The canids were represented by larger taxa in the form of Canis arnensis, C. mosbachensis and C. falconeri, hence the term 'wolf' event coined by Azzaroli (1983). This transition was reinforced around $0.9 \mathrm{Ma}$ by the first European appearances of the living leopard, Panthera pardus, and Crocuta crocuta, part of the changes in the fauna that characterised the 'endVillafranchian event' of Azzaroli (1983). Previous listings have shown the earliest European appearance of the lion, Panthera leo, as occurring also at this time (Turner, 1995), based on data from the southern French locality of Le Vallonnet. It is now clear that this identification was in error and based on an incorrect measurement of what is more probably a canine tooth of P. gombaszoegensis (Moulle, 1998), and the oldest current European record is now at the Italian site of Isernia la Pineta in the earlier part of the Middle Pleistocene (Sala, 1990) (see Fig. 1).

The change at 1.8 Ma is a considerable turnover of the large carnivore guild, but it appears to have had little effect on the two machairodont cats, which continued to share the felid section of the guild with the cheetah and the newly arrived $P$. gombaszoegensis. The extinction of Megantereon is unclear; it was still active at Untermassfeld in Germany at close to 1.0 Ma and it has been reported from two later sites in France and Italy. The increase in overall taxon numbers at the end of the Lower Pleistocene and during the early half of the Middle Pleistocene, with the co-occurrence of many of the older species alongside the modern taxa, comes to an end at around $0.4 \mathrm{Ma}$, with the final demise of what were then the older members of the guild. This period sees the last of $H$. latidens, $P$. gombaszoegensis and A. pardinensis along with Pliocrocuta perrieri, Pachycrocuta brevirostris and various dogs, leaving a European community broadly similar in membership and structure to that of East Africa today. Many of these archaic species had become extinct in Africa at $1.5 \mathrm{Ma}$, so Europe during the Quaternary was essentially a final flourish for these animals, although some immigration from Asia can be inferred as both $A$. pardinensis ( $\mathrm{O}^{\prime}$ Regan, unpublished) and Pliocrocuta perrieri reappeared after earlier European extinction events.

In palaeoecological terms, Megantereon is regarded as being a solitary ambush predator, similar in size to the modern leopard (Turner and Antón, 1997). Work by Lewis (1997) on postcranial remains suggests that it was similar in build and habit to the modern jaguar and is likely to have inhabited forest environments. Pachycrocuta brevirostris was a large, group-living hyaenid which probably specialised in aggressive scavenging in open environments (Turner and Antón, 1996). Acinonyx pardinensis was essentially the same as the modern cheetah, although some $50 \%$ larger, whereas Homotherium was a large, possibly group living cat (Turner and Antón, 1997). The second hyaenid species, Pliocrocuta perrieri, was probably similar to the modern brown hyaena, a species that essentially is solitary and confined to the southern African subregion (Turner, 1990).

Modern jaguar life history data and home range sizes have been used as a proxy for Panthera gombaszoegensis, the cat upon which the remainder of this analysis is based. This felid was chosen because it was a medium sized animal, larger than the leopard and Megantereon, but smaller than the lion and Homotherium. It was probably a solitary animal and therefore its population ecology is easier to model than social cats such as the lion. In addition, it has often been thought to be a forest dwelling cat, with similar habits to the modern jaguar, although recent work ( $\mathrm{O}^{\prime}$ Regan, unpublished) suggests that the association between $P$. gombaszoegensis and forested habitats is not as strong as has often been assumed.

\section{Population viability analysis using VORTEX}

We have used the stochastic simulation model VORTEX (Lacy, 1999) to calculate the probability of extinction for

\begin{tabular}{l}
\multicolumn{1}{c}{ Age (Ma) } \\
\hline FELIDAE \\
Acinonyx pardinensis \\
Panthera gombaszoegensis \\
Panthera leo \\
Panthera pardus \\
Homotherium latidens \\
Megantereon cultridens \\
HYAENIDAE \\
Pliocrocuta perrieri \\
Pachycrocuta brevirostris \\
Chasmaporthetes lunensis \\
Crocuta crocuta
\end{tabular}

2.0

1.5

1.0

0.5

0.0

Figure 1 The temporal distribution of large European carnivores in the Pleistocene. Dotted line in Megantereon distribution indicates uncertainty about the extinction date of this animal 
a large cat over a period of $1000 \mathrm{yr}$. This program is one of several commonly used in conservation biology to assess or predict the risk of extinction for endangered species, a technique known as population viability analysis (PVA). In the following analysis life history data for the modern jaguar (from Seymour, 1989) are used as a substitute for the similar sized Pleistocene pantherine Panthera gombaszoegensis.

VORTEX is a Monte Carlo simulation model that tracks the fate of each animal in a population in an independent manner. The probability of each individual dying or reproducing is drawn randomly from a binomial distribution that has a mean set by life history data input by the user. Environmental variation in the carrying capacity $(K)$ is modelled as a normal distribution (Miller and Lacy, 1999). VORTEX was specifically designed for vertebrate populations of low fecundity and long life span and as such is very suitable for modelling big cat populations. It has been widely used in conservation biology for modelling the expected time to extinction of small populations of conservation concern. Retrospective tests using data from long-term studies of vertebrate populations suggests that its predictions are 'surprisingly accurate' at least for well-studied populations (Brook et al., 2000). Even critics of such approaches appear happy that PVAs are suitable for 'exploring theoretically the implications of model assumptions on extinction probabilities' (Coulson et al., 2001). This is the way we have used VORTEX in the current paper.

We have modelled two sizes of refugium. The first is an area of $180000 \mathrm{~km}^{2}$ approximately equivalent to the Italian peninsula, and the second an area of $32000 \mathrm{~km}^{2}$ equivalent to the Corsica-Sardinia Mediterranean island complex (Blondel and Aronson, 1999). These areas do not take into account the topography of the landmasses nor Pleistocene sea-level changes but do provide a useful baseline from which to work. These refugia have been used because the limitations of population sizes that can be modelled by VORTEX and associated computing constraints mean that the Balkan and Iberian peninsulae are too large to be analysed in this way.

Range-size data for extant large cat species are given in Table 1, showing that territory sizes are highly variable within each species and between sexes. Male and female cats have been treated separately, as in many cases the territory of a single male will overlap that of several females (Kitchener, 1991). For the purpose of our model we have assumed that female territories tessellate and do not overlap. In order to estimate the number of cats within each refugium we calculated the minimum, median and maximum number

Table 1 Range size of modern large cats and calculations of the number of territories available in the Italian peninsula during a glacial maximum (range size data from Hoogesteijn and Mondolfi, 1992)

\begin{tabular}{llcrrr}
\hline Cat & Sex & Range $\left(\mathrm{km}^{2}\right)$ & \multicolumn{3}{c}{ Number of territories } \\
\cline { 3 - 6 } & & & Minimum & Median & Maximum \\
\hline \multirow{2}{*}{ Lion } & Female & $19-400$ & 450 & 859 & 9473 \\
Jaguar & Male & $28.5-158.5$ & 1135 & 1925 & 6315 \\
& Female & $9.5-168$ & 1071 & 2031 & 18947 \\
Leopard & Male & $9-63$ & 2857 & 5000 & 20000 \\
\multirow{2}{*}{ Siberian tiger } & Memale & $8-60$ & 3000 & 5294 & 22500 \\
& Male & $800-1000$ & 180 & 200 & 225 \\
Cheetah & Female & $100-400$ & 450 & 720 & 1800 \\
& Female & $50-65$ & 2769 & 3130 & 3600 \\
\hline
\end{tabular}

of territories available by dividing the overall area of each refugium by the range size (Table 1 ). We have assumed that all territories were occupied and that all territorial males had the opportunity to breed.

Our model is based on the simplifying assumption that the landscape was homogeneous, yet we know that this would not be the case. Variability in range size is largely the result of the availability of prey and suitable habitat. We cannot be sure of prey availability in the past, but it is probable that prey species in refugia would have been subject to the same problems of small populations and inbreeding as the carnivores. Therefore the median range sizes have been used as the basis for the following models, as the maximum population would be relevant only if the entire refugium was optimal habitat, whereas the minimum population may be too pessimistic, as it is based on animals living in suboptimal conditions today.

One of the major conservation concerns about small populations is often assumed to be inbreeding depression (Caughley, 1994; Simberloff, 1998). This is the reduction in fitness sometimes observed when young are produced by matings between close relatives. VORTEX models inbreeding depression in two ways, a reduction in cub survival owing to lethal alleles and a general reduction in fitness owing to lack of heterozygous advantage (Miller and Lacy, 1999). We have used the VORTEX default values of 3.14 lethal equivalents and $50 \%$ reduction in heterozygosity in our model (Miller and lacy, 1999). As no cub mortality data are available for jaguars, we have set cub mortality at $50 \%$ in all simulations; this figure was based on estimates of mortality for two other pantherine species. Schaller (1972) suggested that $50 \%$ of lion cubs fail to reach maturity, and Bailey's (1993) study of leopards estimated a minimum cub mortality of $50 \%$. Sensitivity analysis of our smaller refugium model (data not shown) suggested that cub mortality over $45 \%$ led to the majority of populations becoming extinct whereas mortalities less than $45 \%$ greatly increased survival.

Lack of suitable life history data prevented us from modelling density dependent population dynamics. Prior to the version of VORTEX used in our model (Version 8) density dependence has not been an option, and therefore most published VORTEX simulations have used a ceiling carrying capacity $(K)$ to regulate the population (Chapman et al., 2001). This is the approach we have used in building our model, applying a standard deviation of $5 \%$ to the carrying capacity for all simulations, as computational constraints prevented us using a larger figure for our biggest refugium. Adding density dependence is likely to increase the survival of a population (McCallum et al., 2000; Chapman et al., 2001). Other than the variation about $K$ described by the standard deviation, we have not used any other environmental variations (either environmental catastrophes or temporal trends in $K$ ). The value of $K$ was calculated as two times the female population, with the difference between the total number of males and females being taken as the proportion of non-territory holding males within the population, leading to a prediction of approximately $95 \%$ of males contributing to the gene pool.

Each simulation was replicated 500 times over a period of $1000 \mathrm{yr}$ (the maximum period of time allowed by VORTEX). No environmental catastrophes were included although it is probable that refugial populations would be subject to disease, starvation and other factors, which have been shown to affect many modern large mammal populations (Young, 1994). The absence of catastrophes is likely to increase the chances of population persistence. 


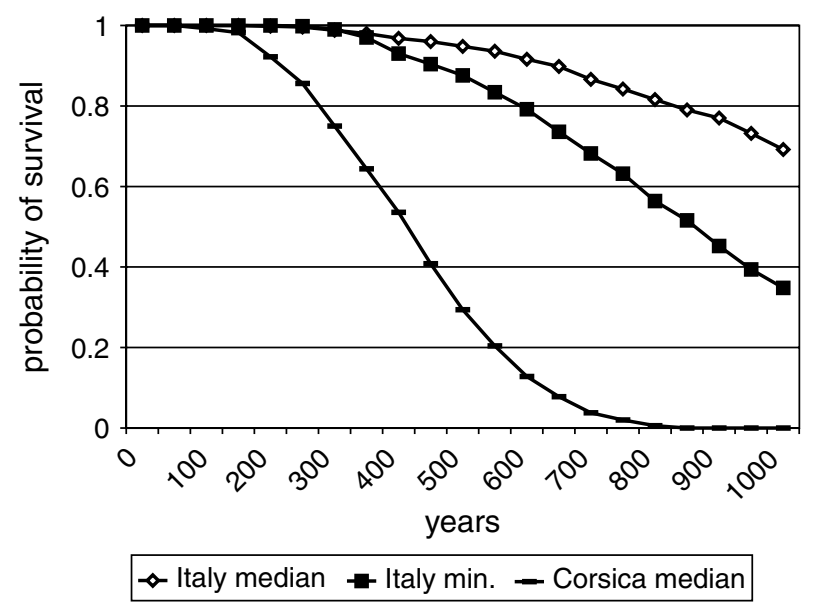

Figure 2 Results of three different scenarios over a timespan of $1000 \mathrm{yr}$. Survival probabilities are calculated as the percentage of populations surviving after 500 iterations. These models were constructed using a carrying capacity of 4062 cats for Italy median, 2206 for Italy minimum and 772 for Corsica-Sardinia median, with a standard deviation of $5 \%$

\section{Model results}

Figure 2 shows the probability of survival for three populations, the minimum and median populations for Italy and the median population for Corsica-Sardinia. From this it is apparent that the survival of a large cat species at the population densities used in this simulation would be greatly dependent on chance in an area the size of Italy and that the probability of survival to $1000 \mathrm{yr}$ on even the largest Mediterranean island would be extremely low.

The effects of inbreeding on a population are illustrated in Fig. 3. We have used the smaller land mass to illustrate this and it is clear that without inbreeding effects the chances of survival for a particular species are greatly improved, although they are still not certain. A similar effect was seen for the median Italian population, where the probability of survival went from $69 \%$

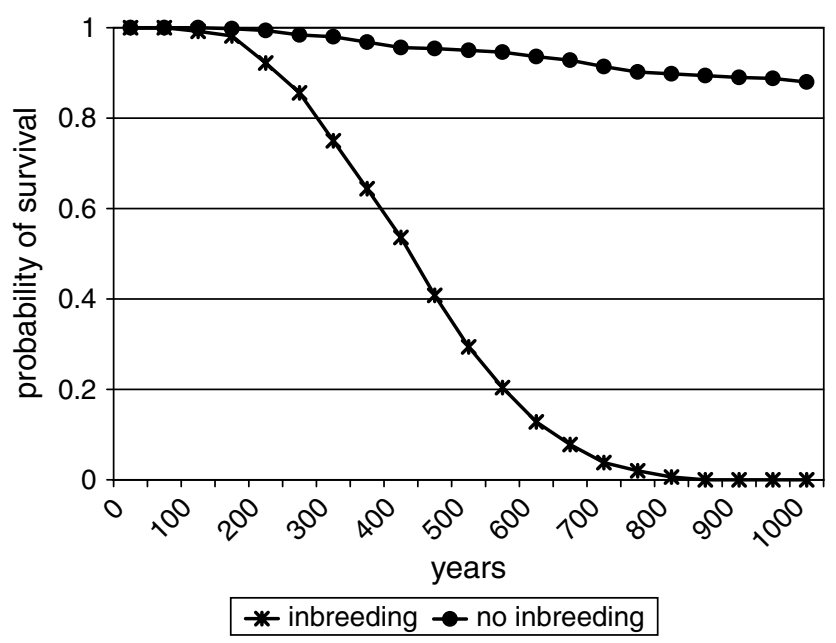

Figure 3 Results of our model for two Corsica-Sardinian populations with and without inbreeding over a period of $1000 \mathrm{yr}$. Survival probabilities are calculated as the percentage of populations surviving after 500 iterations. All parameters were the same for each model ( $K=722$ cats with a standard deviation of $5 \%$ ) with the exception of inbreeding

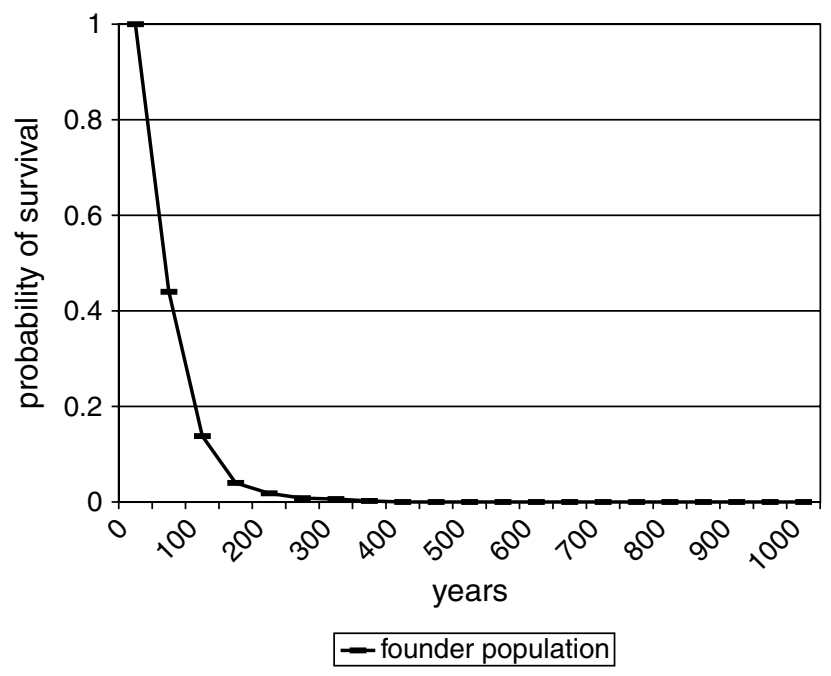

Figure 4 Results of our model for a founder population of 20 cats (with equal numbers of males and females) on Corsica-Sardinia. Parameters were the same as those for the inbreeding model in Fig. 3

to $99 \%$ when inbreeding depression was removed from the model (data not shown).

We modelled a plausible founding population of 20 individuals (with a 1:1 sex ratio) on Corsica-Sardinia, as shown in Fig. 4. It is apparent from this graph that the persistence of small populations of large carnivores over extended time periods is highly unlikely.

\section{Discussion}

It is clear from our modelling that the area available within a refugium has a distinct effect on the survival probabilities of a particular population. On Corsica-Sardinia all replicated populations became extinct within $1000 \mathrm{yr}$, whereas in Italy some $69 \%$ of replicated populations were surviving at the end of the simulation. However, a glacial maximum would have lasted longer than $1000 \mathrm{yr}$ and survival over this period is likely to be less than the results of our $1000 \mathrm{yr}$ simulations.

Van Kolfschoten (1995) estimated that $12 \%$ of the glacial-interglacial cycle could be regarded as at glacial maximum. In a Milankovich cycle of approximately $100000 \mathrm{yr}$ this equates to $12000 \mathrm{yr}$. The migration routes in and out of the Iberian and Italian peninsulas effectively would have been blocked by ice sheets on the Pyrenees and Alps during this period. It is probable that a few individuals could have crossed the steppe areas created by the low sea-level between Italy and the Balkans, but for species that were primarily forest dwelling or ambush hunters this would have been a challenge. Therefore, we can regard the Iberian and Italian peninsulas as being capped by the ice sheets on the mountains, with effectively no migration between populations for a period of some $12000 \mathrm{yr}$, a situation that would have resulted in inbreeding. However, over time natural selection can remove deleterious recessive alleles and this partially will be the case for a population that has been through a genetic bottleneck as a result of small population size (Simberloff, 1998). Indeed VORTEX models the removal of such recessive alleles through the course of a simulation. A Corsica-Sardinia model with and without inbreeding (Fig. 3) illustrates the importance of inbreeding in causing extinctions in refugial populations. Studies of modern felids such as the cheetah also have suggested that inbreeding 
plays a very important role in the survival of small populations (Menotti-Raymond and O'Brien, 1993). During the course of the Quaternary period our cat populations are likely to have gone through repeated genetic bottlenecks in various glacial refugia. This should have led to a purging of the lethal recessive alleles and our results illustrate that decreased inbreeding depression should have increased a population's ability to survive in a glacial refugium as the Quaternary period progressed. It is plausible that the final extinction of Megantereon (the smaller sabretoothed cat) may have been a consequence of a small population being forced through this first bottleneck at ca. 0.8 Ma. This date is important because it is at this point that the glacial cycle intensifies, with very marked oscillations between the warmest and coldest periods, rather than the smaller swings seen prior to this (Shackleton, 1995).

Lewis (1997), in a review of the postcranial adaptations of Megantereon, concluded that it was a forest dwelling species with habits similar to those of the modern jaguar. If this is so, then it would have been particularly vulnerable to extinction as this is the habitat that would have undergone most reduction during a glacial period. It is worth noting that those species which survived the first major glaciations at ca. 0.8 Ma persisted until approximately $0.4 \mathrm{Ma}$, indicating that surviving in the first glacial refugium may have increased these animals' chances of survival in the similar conditions of the later Pleistocene. Our model suggests that a reduction in the number of recessive alleles is a possible mechanism for this. Recent work by Rohling et al. (1998) on the foraminiferal record from the Red Sea has indicated that the $0.4 \mathrm{Ma}$ glaciation saw a reduction in sea-level of 140 m, 20 m lower than the last glacial maximum, indicating an increase in ice volume. This would have affected the animals, as although the refugia would not have been substantially enlarged because the Mediterranean shelves too steeply, the ice caps on the Alps and Pyrenees may have been larger, firmly sealing off these two peninsulas and reducing tree cover still further. The intensification of the glacial cycle and decrease in suitable habitat at the $0.4 \mathrm{Ma}$ glacial coincides with the extinction of the last remaining archaic carnivores, including $P$. gombaszoegensis, potentially as a result of smaller refugia sizes. The three species left (lion, leopard and spotted hyaena) are those that are known in Africa today.

Different refugia would have had slightly differing conditions, such as the suggestion of aridity in the Iberian peninsula seen in both pollen (Bennett et al., 1991) and faunal (Agustí and Moyà-Solà, 1992) evidence. Poor conditions for one species may have favoured another, e.g. the dominance of open environments may have been advantageous to cursorial hunters such as the fossil cheetah (Acinonyx pardinensis) but cats that prefer more forested environments may have been at a disadvantage. Several studies have highlighted the importance of wooded areas to extant large cats. Schaller (1972) analysed the success of lion hunts in relation to vegetation type and found that an average of $25 \%$ of prey were taken in grassland less than $30 \mathrm{~cm}$ high, whereas the majority of other kills were in thickets or riparian habitats. Leopards cache their kills in trees to avoid scavengers, a behaviour that is likely to have existed during the Pleistocene (Brain, 1981). In addition, jaguars, leopards and tigers all drag their prey into dense undergrowth to store it or to avoid scavengers (Sunquist and Sunquist, 1989). It appears then, that a reduction of wooded or thicket areas may have made prey capture more difficult and the resultant kills more vulnerable to scavengers such as the spotted hyaena (Crocuta crocuta). Such an occurrence may explain the loss of the fossil cheetah (Acinonyx pardinensis) between 0.8 and $0.5 \mathrm{Ma}$ in Europe (see Fig. 1). The extant cheetah loses some of its prey, but more importantly many of its cubs, to competitors such as the spotted hyaena and lion (lions were responsible for $73.2 \%$ of cheetah cub deaths of known causes in the Serengeti (Caro, 1994)). The adult cheetah can avoid many such conflicts by actively moving away from these predators when it detects them (Durant, 1998). However, in a relatively small area and with high pressure on the prey resource, and two open environment adapted and group living hyaenas (Pachycrocuta brevirostris and Crocuta crocuta), the difficulties of retaining kills and avoiding predators may have led to the local extinction of cheetah in refugia within a relatively short time period. Indeed, although it is never a common species, no fossils of the cheetah have been reported from any of the later Pleistocene refugial areas, although it is known from two sites further north (Hundsheim, Austria; Mosbach 2, Germany (Wolsan, 1993)). These findings suggest that the fossil cheetah may have been an immigrant from Asia during interglacials, when tree cover and a greater overall area may have enabled it to avoid other predators, but its chances of survival in small-scale refugial areas were limited. However, our model illustrates that even in identical refugia, comparable populations could have a different history (extinction or survival) in different glacials owing to chance effects.

The speed of extinction under certain circumstances might make vulnerable populations such as the cheetah palaeontologically invisible. To take an example, our smallest refugium (32 $000 \mathrm{~km}^{2}$ ) was the size of the largest Mediterranean island complex and yet all populations became extinct before the end of the simulation. In the case of the small founding population (Fig. 4) the demise was even swifter-all populations were extinct within $400 \mathrm{yr}$, with a mean time to extinction of $61.08 \mathrm{yr}$. The chances of finding such a fast extinction event in the fossil record must be remote. This result has implications for our understanding of the colonisation of the Mediterranean islands. It usually is assumed that elephants are present on these islands because they can swim, but so can many other mammals, including tigers and jaguars (Mazak, 1981; Seymour, 1989). Is it likely that no large carnivores ever reached these islands? Or is it perhaps more plausible that those animals that did were unable to form a self-sustaining population and became extinct so swiftly that we cannot detect them in the palaeorecord? We cannot be sure of the answer, but our results suggest that the second possibility of rapid extinction may well have occurred on some islands in the past. It is probable that small populations such as these also would have been unable to survive in the small northern refugia. Although the large carnivores were found in Italy, the Balkans and Iberia, we are not aware of any fossil records of these animals from the Mediterranean islands.

We emphasise that the survival of a specific species within a particular refugium during any one glaciation may have included a large element of chance. Such a hypothesis was tested for tree survival in Europe by Birks and Line (1993) who used pollen data to show that the distribution of tree taxa in refugia can be viewed as primarily stochastic. We have shown that the survival of a large population (>4000 cats) is not certain, with a $69.2 \%$ probability of survival over $1000 \mathrm{yr}$. It is also worth noting that our model is largely optimistic as, with the exception of density dependence, the assumptions made in constructing our model would be likely to promote increased population survival rather than precipitate their extinction. We acknowledge the likelihood that there would be clumped populations in some areas and probable absence of predators in others rather than an even spread of cats across the landscape. Forested areas existed only as small pockets rather than a mass of trees (Willis, 1996), which would lead to smaller population sizes and thus increase the likelihood of extinction. 
The results discussed above are based upon areas the size of the Italian peninsula and Corsica-Sardinia; the Balkan areas and the Iberian peninsula are larger and may have proved capable of supporting greater populations. However, even large areas would be vulnerable to stochastic processes such as those we have illustrated.

\section{Conclusions}

Modelling a large cat population has provided a new insight into the processes of extinction that may have occurred in Europe during the Middle Pleistocene. The sheer size of the three large European refugia of the Balkans, Iberia and Italy would incline one to think that animals that were present during a glaciation would survive until the following interglacial, but we have shown that this is not necessarily the case and that chance could still play a large role in population survival. Such stochastic effects may indicate how such a large guild of carnivores may have managed to persist for so long, with different species surviving in different refugia.

We also draw attention to the possible declining importance of inbreeding depression during repeated glacial-interglacial cycles and the possibility that the lack of large carnivores from the Mediterranean islands may be due to swift extinction rather than a lack of colonisation.

In applying modern conservation biology techniques to palaeontological data we have gained a new perspective on the extinction of large carnivores and we hope that we have shown the potential for using such interdisciplinary approaches to explore a wide variety of palaeontological questions.

Acknowledgements We are grateful to Simon Dowell for introducing us to VORTEX and critically reviewing this manuscript. We would also like to thank the referees, K. Bennett and T. van Kolfschoten for their useful comments.

\section{References}

Agustí J, Moyà-Solà S. 1992. Mammalian dispersal events in the Spanish Pleistocene. Courier Forschungs Institut Senckenberg 153: 69-77.

Azzaroli A. 1983. Quaternary mammals and the 'end Villafranchian' dispersal event-a turning point in the history of Eurasia. Palaeogeography, Palaeoclimatology, Palaeoecology 44: 117-139.

Bailey TN. 1993. The African Leopard-Ecology and Behavior of a Solitary Felid. Columbia University Press: New York.

Bennett KD, Tzedakis PC, Willis KJ. 1991. Quaternary refugia of north European trees. Journal of Biogeography 18: 103-115.

Bilton DT, Mirol PM, Mascheretti S, Fredga K, Zima J, Searle JB. 1998. Mediterranean Europe as an area of endemism for small mammals rather than a source for northwards postglacial colonisation. Proceedings of the Royal Society London, Series B 265: $1219-1226$.

Birks HJB, Line JM. 1993. Glacial refugia of European trees - a matter of chance? Dissertationes Botanicae 196: 283-291.

Blondel J, Aronson J. 1999. Biology of the Mediterranean Region. Oxford University Press: Oxford.

Brain CK. 1981. The Hunters or the Hunted? An Introduction to African Cave Taphonomy. University of Chicago Press: Chicago.

Brook BW, O'Grady JJ, Chapman AP, Burgman MA, Akçakaya HR, Frankham R. 2000. Predictive accuracy of population viability analysis in conservation biology. Nature 404: 385-387.

Caro TM. 1994. Cheetahs of the Serengeti Plains-Group Living in an Asocial Species. University of Chicago Press: Chicago.
Caughley G. 1994. Directions in conservation biology. Journal of Animal Ecology 63(2): 215-244.

Chapman AP, Brook BW, Clutton-Brock TH, Grenfell BT, Frankham R. 2001. Population viability analyses on a cycling population: a cautionary tale. Biological Conservation 97: 61-69.

Cohen JE, Pimm SL, Yodzis P, Saldana J. 1993. Body sizes of animal predators and animal prey in food webs. Journal of Animal Ecology 62: $67-78$.

Coulson T, Mace GM, Hudson E, Possingham H. 2001. The use and abuse of population viability analysis. Trends in Ecology and Evolution 16(5): 219-221.

Durant SM. 1998. Competition refuges and coexistence: an example from Serengeti carnivores. Journal of Animal Ecology 67: 370-386.

Geikie J. 1881. Prehistoric Europe, a Geological Sketch. Edward Stanford: London.

Hewitt GM. 1999. Postglacial re-colonisation of European biota. Biological Journal of the Linnean Society 68: 87-112.

Hoogesteijn R, Mondolfi E. 1992. The Jaguar. Armitano Editores: Caracas.

Huntley B, Webb T. 1989. Migration: species response to climatic variations caused by changes in the earth's orbit. Journal of Biogeography 16: 5-19.

Kitchener A. 1991. The Natural History of the Wild Cats. Christopher Helm: London.

Lacy RC. 1999. VORTEX program website. http://pw1.netcom.com/ rlacy/vortex.html [accessed 20 March 2002].

Lewis M. 1997. Carnivoran paleoguilds of Africa: implications for hominid food procurement strategies. Journal of Human Evolution 32: $257-288$.

Mazak V. 1981. Panthera tigris. Mammalian Species 152: 1-8.

McCallum H, Kikkawa J, Catterall C. 2000. Density dependence in an island population of silver eyes. Ecology Letters 3: 95-100.

Menotti-Raymond M, O'Brien SJ. 1993. Dating the genetic bottleneck of the African cheetah. Proceedings of the National Academy of Sciences, USA 90: 3172-3176.

Miller PS, Lacy RC. 1999. VORTEX: a Stochastic Simulation of the Extinction Process. Version 8 User's Manual. Conservation Breeding Specialist Group (SSC/IUCN): Apple Valley, MN.

Moulle P-E. 1998. Les grands mammiféres de la Grotte du Vallonnet (Roquebrune-Cap Martin, Alpes-Maritimes). Synthése des études anterieures et nouvelles determinations. Bulletin du Musée D'Anthropologie Prehistorique de Monaco 39: 29-36.

Reid C. 1899. The Origin of the British Flora. Dulau: London.

Rohling EJ, Fenton M, Jorissen FJ, Bertrand P, Ganssen G, Caulet JP. 1998. Magnitudes of sea-level lowstands of the past 500000 years. Nature 394: $162-165$.

Sala B. 1990. Panthera leo fossilis (Reich, 1906) (Felidae) di Isernia la Pineta (Pleistocene moyen inferieur d'Italie). Geobios 23: 189-194.

Schaller GB. 1972. The Serengeti Lion: a Study of Predator-Prey Relations. University of Chicago Press: Chicago.

Seymour KL. 1989. Panthera onca. Mammalian Species 340: 1-9.

Shackleton NJ. 1995. New data on the evolution of Pliocene climatic variability. In Paleoclimate and Evolution with Emphasis on Human Origins, Vrba ES, Denton GH, Partridge TC, Burckle LH (eds). Yale University Press: New Haven; 242-248.

Simberloff D. 1998. Small and declining populations. In Conservation Science and Action, Sutherland WJ (ed.). Blackwell: Oxford; $116-151$.

Stewart JR, Lister A. 2001. Cryptic Northern refugia and the origins of the modern biota. Trends in Ecology and Evolution 16: 608-613.

Sunquist ME, Sunquist FC. 1989. Ecological constraints on predation by large felids. In Carnivore Behavior, Ecology and Evolution, Gittleman JL (ed.). Cornell University Press: Ithaca; 283-301.

Taberlet P, Fumagalli L, Wust-Saucy A, Cossons J. 1998. Comparative phylogeography and postglacial colonization routes in Europe. Molecular Ecology 7: 453-464.

Turner A. 1990. The evolution of the Guild of larger terrestrial carnivores during the Plio-Pleistocene in Africa. Geobios 23: $349-368$

Turner A. 1995. The Villafranchian large carnivore guild: geographic distribution and structural evolution. I/ Quaternario 8: 349-356.

Turner A, Antón M. 1996. The giant hyaena Pachycrocuta brevirostris (Mammalia, Carnivora, Hyaenidae). Geobios 29: 455-468. 
Turner A, Antón M. 1997. The Big Cats and their Fossil Relatives. Columbia University Press: New York.

Turner A, Antón M. 1999. Climate and evolution: implications of some extinction patterns in African and European machairodontine cats of the Plio-Pleistocene. Estudios Geologicos 54: 209-230.

Van Kolfschoten T. 1995. On the application of fossil mammals to the reconstruction of the palaeoenvironment of Northwestern Europe. Acta Zoologica Cracoviensia 38: 73-84.
Willis KJ. 1996. Where did all the flowers go? The fate of the temperate European flora during glacial periods. Endeavour 20: $110-114$.

Wolsan M. 1993. Evolution des carnivores quaternaires en Europe centrale dans leur contexte stratigraphique et paleoclimatique. L'Anthropologie, Paris 97: 203-222.

Young TP. 1994. Natural die-offs of large mammals: implications for conservation. Conservation Biology 8(2): 410-418. 